\title{
Interpretation of the Common MRI Findings in Patients with Painful Knee Joint
}

\author{
Sohel Rana ${ }^{1}$, Mozammel Hossen ${ }^{1}$, Azharul Islamn ${ }^{1}$, See jal Shah ${ }^{1}$, Tanzila Parvin ${ }^{1}$, SM Muraduzzaman ${ }^{1}$, \\ and Mushtaque Ahmed Jalali ${ }^{2}$ \\ ${ }^{1}$ Department of Biomedical Engineering \& Medical Physics, Bangladesh University of Health Sciences, Dhaka, Bangladesh; \\ and ${ }^{2}$ National Institute of Cancer Research \& Hospital, Dhaka, Bangladesh.
}

*Correspondence: $\underline{\text { skohel57@gmail.com }}$

\begin{abstract}
Nowadays knee joint pain is a major public health issue and for an appropriate treatment option, it is important to have a clear understanding of the cause of pain as well as to identify the exact location of the pain. In the initial evaluation of acute knee pain, radiological findings help physicians in taking decisions regarding appropriate treatment. Besides conventional radiography and computed tomography (CT), Magnetic resonance imaging (MRI) is often used to diagnose the reason for knee problems. This study it is tried to evaluate the common MRI findings in patients with painful knee joints. The sample population comprised 77 outpatients had an age range between 14 to 66 years, representing male $70.13 \%$ and Female $29.87 \%$. The study shows that the maximum numbers of patients were in the 26-30 years age group, which exposed that young people are more affected with knee pain. In this study, it is found that joint effusion is the most common pathology frequently found in $59.74 \%$ of patients followed by meniscus injury $53.24 \%$, anterior cruciate ligament (ACL) tear $36.06 \%$, Lateral meniscus injury $16.88 \%$, Posterior cruciate ligament (PCL) tear $7.8 \%$, Bone marrow contusion 22.07\%, Osteoarthritis 12.98\%, Medial collateral ligament (MCL) injury 3.89\%, Lateral collateral Ligament (LCL) 0\%, Fracture 6.49\%, Chondromalacia1.3\%, Baker cyst 1.3\%. Though knee pain can be diagnosed by other imaging modalities, MRI can often provide strong evidence to support one.
\end{abstract}

Keywords: Painful knee, Radiology, Magnetic resonance imaging, CT, Ligament injuries, and Osteoarthritis.

\section{INTRODUCTION:}

The number of people coming with complains of knee joint pain are increasing day by day. Knee joint is very important joint of a human body which has complex articulation characterized by the presence of ligamentous and meniscal structures. The stability and mobility of human body mostly depends on knee joint. People may be affected by knee pain at any age. High prevalence of knee joint pain was reported by various authors (Dawson et al., 2004; Saraswathi, 2009).
Osteoarthritis of the knee is a major public health issue that causes chronic pain and disability. It is the common causes of morbidity, disability, and work loss in rural and urban communities of Bangladesh (Haq et al., 2008). Knee pain can be caused by a sudden injury, an overuse injury, or by an underlying condition, such as arthritis. Treatment will vary depending on the cause. Symptoms of knee injury can include pain, swelling, and stiffness. To diagnose the cause of knee pain, radiology imaging plays an important role (Campbell et al., 2001). 
Plain X-ray can establish fractures and degenerative changes of the knee. In cases of knee joint trauma, clinical examination along with radio-graphs and even CT scan is not enough to diagnose many internal conditions of this joint. MRI, due to its excellent soft tissue contrast resolution and multi-planar imaging capabilities provides significant advantages over other imaging techniques in the evaluation of traumatic injuries of knee joint (Yadav and Kachewar, 2013; Prickett et al., 2001).

MRI can accurately diagnose the ligament injuries of knee joint, which is an ideal technique in the diagnosis of ligament injuries, and should be used as a routine examination method (Pompan, 2012). So, MRI affects the diagnosis and management of the knee injuries by decreasing the number of arthroscopic procedures, improving clinician diagnostic certainty, and assisting in management decision (Kamran et al., 2015). It has been found that the disruption of a knee ligament is commonest pathology in patients having post traumatic knee pain (Roy et al., 2020). It is important to develop a mechanistic approach to associate the imaging findings with their anatomic relevance (Miller and $\mathrm{Yu}, 2010)$.

MRI is a type of scan that uses a magnetic field, radio waves, and a computer to create detailed pictures of the inside of your body. Unlike an X-ray, which takes pictures of your bones, a knee MRI lets physician see bones, cartilage, tendons, ligaments, muscles, and even some blood vessels. The test can show a range of problems, including: Damaged carti-lage, Torn tendons or ligaments, Bone fractures, Oste-oarthritis, Infections, Tumors, etc. MRI is a non-invasive imaging technique that does not involve exposure to ionizing radiation (Peterfy et al., 2004).

Knee joint pain may either have traumatic origin or non-traumatic origin like infection or inflammation. Optimum treatment is hampered sometimes due not to identify the exact lesion causing pain. MRI can demonstrate the exact nature and extent of bony as well as soft tissue abnormality (Escala et al., 2006). This has increased the use of MRI in evaluation of patients of knee pain (Mehta et al., 2015). Fig 1 shows MRI of knee diagnosing moderate joint effusion whereas Fig 2 shows normal MRI of knee joint.

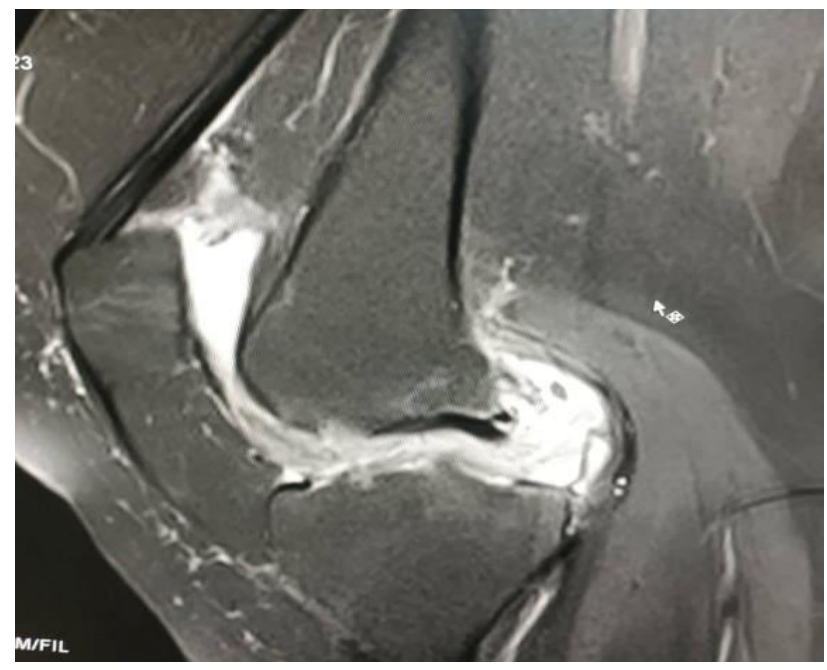

Fig 1: Moderate joint effusion.

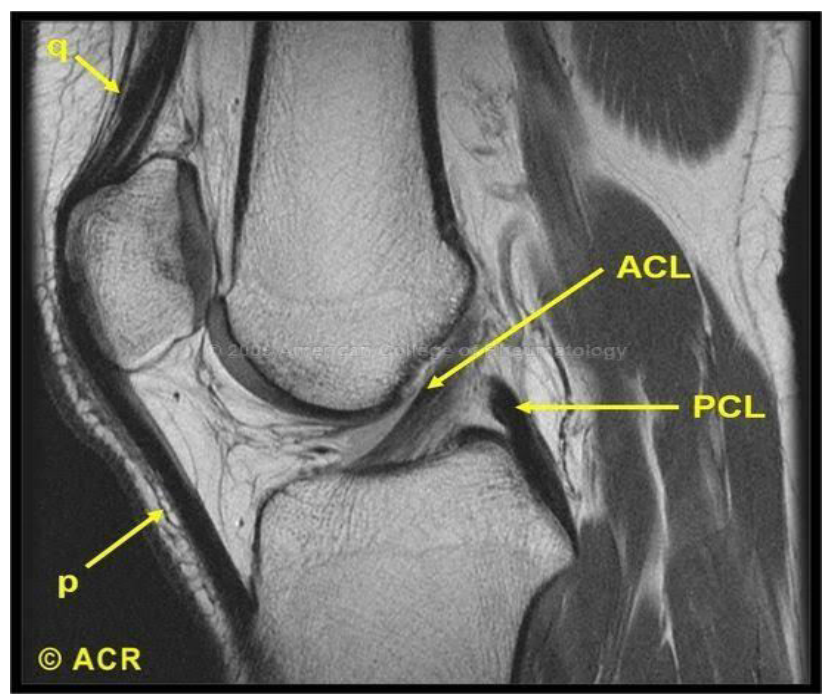

Fig 2: Shows normal ACL and PCL.

\section{MATERIALS AND METHODS:}

This study consists of 77 adult cases from MRI department, Popular Medical College and Hospital. All patients had prior history of knee pain, injuries (Sports, Trauma), Swelling, difficulty in bending knee etc. Siemens Magnetom Avanto1.5 tesla MRI machine was used for diagnosis of patients' painful knee. The following protocols were used:

- T2-tse-sagital,coronal,and axial plan

- T1-tse-sagittal,coronal,and axial plan

- PD-tse- fs- sagittal, coronal, and axial plan

- PD-tse -sagittal plan

- T2-tse-sag-p2-2mm (Especially for ACL injury). 
* Inclusion crite ria: Patients of either sex with age more than 14 having acute or chronic painful knee.

* Exclusion criteria: Patients, who could not cooperate for MRI examination, have undergone prior surgical procedures and who had metallic implant or metallic situ.

All images were reported by radiologists, and a consensus diagnosis was given by two radiologists in controversial cases. After collection, Data was checked, verified, and processed to reduce error. Then it was analyzed by computer.

\section{RESULTS:}

Among all imaging technique, MRI becomes the preferred imaging technique for the evaluation of the painful knee following injury because of its ability to detect soft tissue abnormality (meniscus and cruciate /collateral ligament tears) and fracture that cannot be detected by plain X-Ray. Joint pain is the most common complaint in prior history and the second most common complaint is sports injury. From Table 1 it can be shown that the maximum numbers of patients were in 26-30 years age group and from which it can also be observed that young people are affected more. A number of factors may be involved in this case such as excess weight, lack of muscle flexibility or strength, certain sports or occupations, previous injury, lack of being active, etc.

Table 1: Demonstrating patients according to age group ( $\mathrm{N}=77)$

\begin{tabular}{|c|c|c|c|}
\hline Demographic Data & Variable & Number & Percentage \\
\hline \multirow{12}{*}{ Age } & $<15$ Years & 2 & $2.90 \%$ \\
\hline & $16-20$ Years & 8 & $7.25 \%$ \\
\hline & 21-25 Years & 10 & $13.04 \%$ \\
\hline & 26-30 Years & 15 & $20.29 \%$ \\
\hline & 31-35Years & 13 & $15.94 \%$ \\
\hline & $36-40$ Years & 8 & $10.14 \%$ \\
\hline & $41-45$ Years & 8 & $11.59 \%$ \\
\hline & $46-50$ Years & 3 & $4.35 \%$ \\
\hline & 51-55 Years & 3 & $4.35 \%$ \\
\hline & 56-60 Years & 5 & $7.25 \%$ \\
\hline & $61-65$ Years & 0 & $0 \%$ \\
\hline & $>$ 66Years & 2 & $2.90 \%$ \\
\hline \multicolumn{2}{|c|}{ Total } & 77 & $100 \%$ \\
\hline
\end{tabular}

Table 2: Distribution of patients according to sex and affected side

\begin{tabular}{|c|c|c|c|}
\hline \multicolumn{2}{|c|}{ Male } & \multicolumn{2}{c|}{ Female } \\
\hline Problem in Right knee & Problem in Left knee & Problem in Right knee & Problem in Left knee \\
\hline 33 & 21 & 12 & 11 \\
\hline \multicolumn{2}{|c|}{ Total Male $=54(70.13 \%)$} & \multicolumn{2}{c|}{ Total Female $=33(29.87 \%)$} \\
\hline \multicolumn{2}{|c|}{ Total RT knee $=45(58.44 \%)$} & Total LT knee $=32(41.56 \%)$ \\
\hline
\end{tabular}

Analysis of demographic characteristics shows that in this present study of 77 patients $70.13 \%$ were male and $29.87 \%$ were female (Fig 3). Male are more affected than female. This is because male are generally more active than female and travel a lot. Hence their knees are exposed to more wear and tear.
Also they are at more risk of injury. It also demonstrates that Right knee $(58.44 \%)$ is more affected than left knee $(41.56 \%)$ (Table 2) and the result is opposed the result that was observed by some authors (InCharge, 2013). 


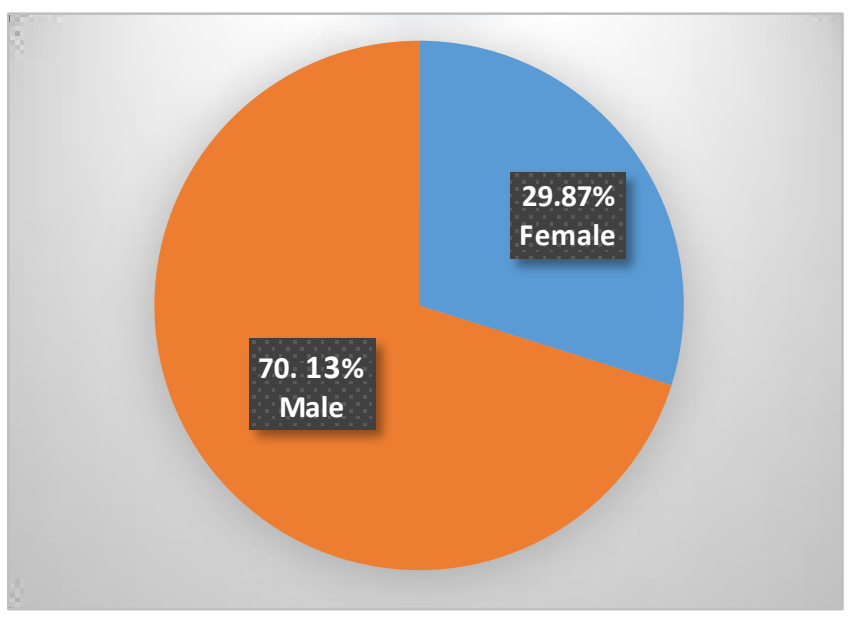

Fig 3: Sex wise distribution of participants.

Table 3: Demonstration of MRI finding of ACL involvement

\begin{tabular}{|c|c|c|}
\hline Findings & No. of Patients & \% \\
\hline Partial Tear & 6 & 22.22 \\
\hline Complete Tear & 21 & 77.78 \\
\hline Total & $\mathbf{2 7}$ & $\mathbf{1 0 0}$ \\
\hline
\end{tabular}

From Table 3 it can be demonstrated that 27 patients have ACL involvement in knee pain and complete ACL tear is more (77.78\%) than partial ACL tear (22.22\%).

Table 4: Distribution of patients having posterior cruciate ligament (PCL) involvement in their knee pain

\begin{tabular}{|c|c|c|}
\hline Findings & No. of Patients & \% \\
\hline Partial Tear & 3 & 30 \\
\hline Complete Tear & 3 & 30 \\
\hline Buckling & 4 & 40 \\
\hline Total & $\mathbf{1 0}$ & \\
\hline
\end{tabular}

It can be observed from Table 4 that out of 10 no of patients having knee pain due to PCL, buckling (40\%) is the common findings.

Table 5: Demonstration of MRI finding of collateral Ligament

\begin{tabular}{|c|c|c|}
\hline Findings & $\begin{array}{c}\text { Medial } \\
\text { collateral Ligament } \\
\text { (MCL) }\end{array}$ & $\begin{array}{c}\text { Lateral } \\
\text { collateral Ligament } \\
\text { (LCL) }\end{array}$ \\
\cline { 2 - 3 } & No. of Patients (\%) & No. of Patients (\%) \\
\hline Normal & $74(96.10 \%)$ & $77(100 \%)$ \\
\hline Tear & $3(3.90 \%)$ & 0 \\
\hline
\end{tabular}

Table 6: Demonstration of meniscus injury involvement found in MRI finding

\begin{tabular}{|c|c|c|}
\hline \multirow{2}{*}{ Findings } & Medial Meniscus & Lateral Meniscus \\
\hline & $\begin{array}{c}\text { No. of Patients } \\
(\%)\end{array}$ & No. of Patients (\%) \\
\hline Anterior horn & $4(5.19 \%)$ & $6(7.79 \%)$ \\
\hline $\begin{array}{l}\text { Posterior } \\
\text { horn }\end{array}$ & $40(51.95 \%)$ & $6(7.79 \%)$ \\
\hline
\end{tabular}

Table 6 showed that medial meniscus injury is in more cases $(54,70.13 \%)$ and it may also be demonstrated that posterior horn is more affected than anterior horn.

Table 7: MRI finding distributed on the involvement of joint effusion

\begin{tabular}{|c|c|c|}
\hline Findings & $\begin{array}{c}\text { No. of } \\
\text { patients }\end{array}$ & Percent \\
\hline Normal & 31 & $40.26 \%$ \\
\hline Small joint effusion & 30 & $38.96 \%$ \\
\hline Mild joint effusion & 7 & $9.09 \%$ \\
\hline Moderate joint effusion & 9 & $11.69 \%$ \\
\hline
\end{tabular}

It may be concluded from Table 7 that Small joint effusion $(30,38.96 \%)$ is very common pathology among patients of painful knee joint.

Table 8: A list of common pathology found in this study

\begin{tabular}{|c|c|c|}
\hline Pathology & $\begin{array}{c}\text { No. of } \\
\text { patients }\end{array}$ & Percentage \\
\hline ACL tear & 27 & 35.06 \\
\hline PCL tear & 6 & 7.8 \\
\hline MCL Injury & 3 & 3.89 \\
\hline LCL Injury & 0 & 0 \\
\hline Joint effusion & 46 & 59.74 \\
\hline $\begin{array}{c}\text { Medial meniscus } \\
\text { injury }\end{array}$ & 41 & 53.24 \\
\hline $\begin{array}{c}\text { Lateral meniscus } \\
\text { injury }\end{array}$ & 13 & 16.88 \\
\hline $\begin{array}{c}\text { Bone marrow } \\
\text { contusion }\end{array}$ & 17 & 22.07 \\
\hline Osteoarthritis & 10 & 12.98 \\
\hline Fracture & 5 & 6.49 \\
\hline Chondromalacia & 1 & 1.3 \\
\hline Baker cyst & 1 & 1.3 \\
\hline $\begin{array}{c}\text { Synovial osteochon- } \\
\text { dromatosis }\end{array}$ & 1 & 1.3 \\
\hline
\end{tabular}


It can be demonstrated from Table 8 and Fig $\mathbf{4}$ that joint effusion is the most common pathology $59.74 \%$ followed by Medial meniscus injury $53.24 \%$, ACL Tear $35.06 \%$, Bone marrow contusion $22.07 \%$.

\section{DISCUSSION:}

Present study was an observational analysis of the various causes of a painful knee detected by MR imaging. In this study, the mean age was 40.5 years and it is male dominance. Our results are in concordance with those of Yadav et al. (2013) who described a mean age of $36.70 \pm 14$ years and a male preponderance in their study (Yadav and Kachewar, 2013). Male preponderance was also seen in study done by some authors (Gimhavanekar et al., 2016; Mansour et al., 2015; Singh et al., 2004).

There is a number of population those had a normal MRI. This might be inclusion of patients with a painful knee instead of just traumatic knee injury. Joint effusions were the commonest soft tissue abnormality found in our study followed by Meniscal tears. Tears involved posterior horn of the medial meniscus more com-monly. The observations are in concordance with the previously reported literature (Bansal et al., 2018; Pasupuleti et al., 2015; Kelly,
2006; Crues et al., 1990; Pame et al., 2017). Tear was the commonest pathology affecting the ACL, most being acute in nature. PCL involvement pathology in our study was $7.8 \%$, which may be compared to the $5.78 \%$ incidence reported by Singh et al. (2004) Buckling $(40 \%)$ is the common findings in PCL involvement. One-third of our patients had bone contusion which compares well with the existing literature (28.3\%) (Wright et al., 1995; Sohail et al., 2015; Mathis et al., 1998). Critical ACL tears were usually due to bone contusions in our study. Similar association was reported previous studies (McCauley et al., 1994; Spindler et al., 1993; Arumugam et al., 2015).

Baker cyst was very less common in present study. MRI detects an associated disorder in cystic cases. An association of popliteal cyst with joint effusion, meniscus tear and ACL tear has been previously reported (Miller et al., 1996; Sansone et al., 1995). MR has been established as an effective non-invasive modality for identifying the knee pathology. The study aimed to highlight the role of MRI in diagnosing the cause of painful knee and strengthen its superiority over the conventional imaging (X-rays) and CT scan thereby ensuring a better clinical management.

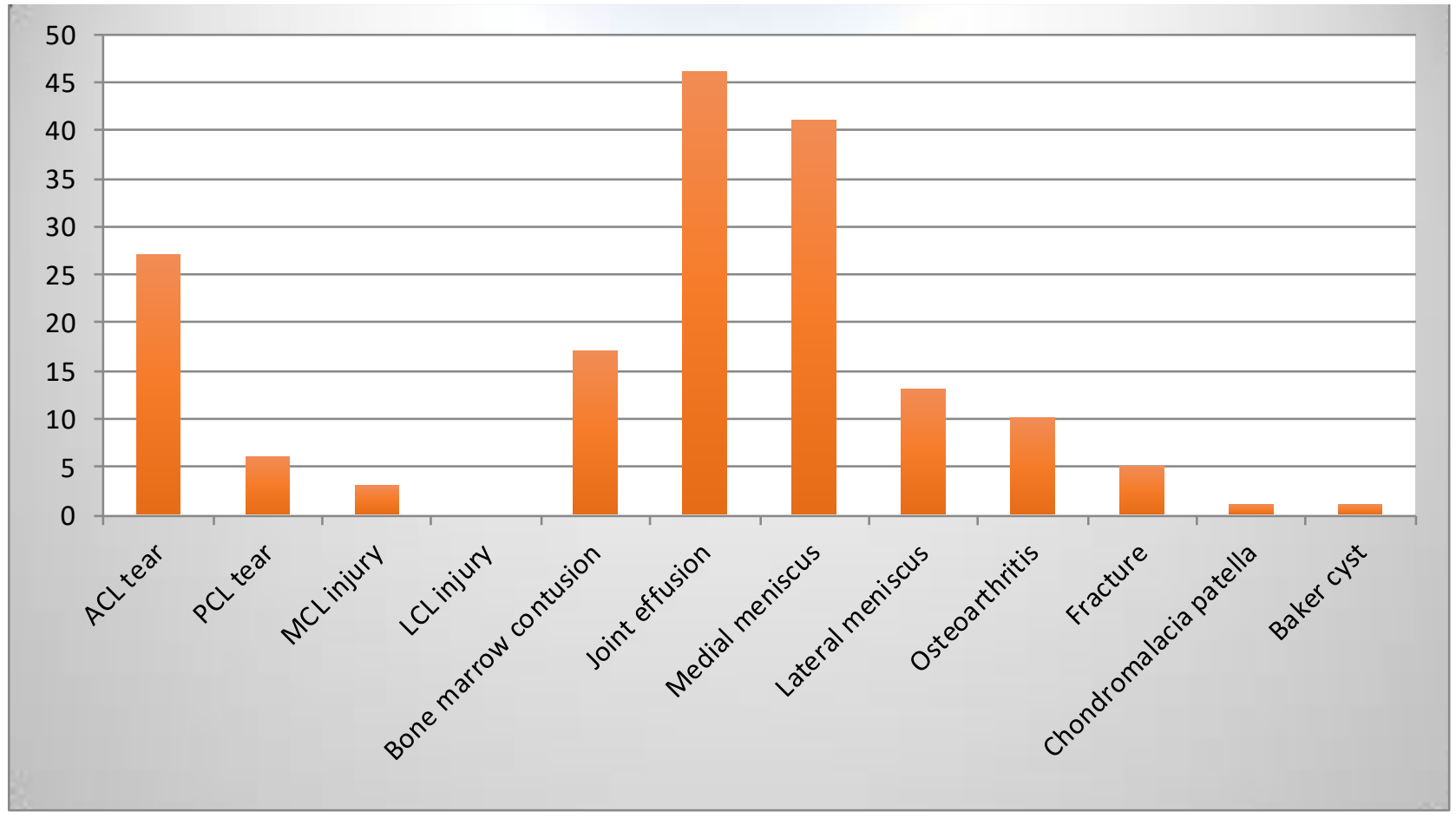

Fig 4: Histogram showing number of cases of different pathology. 


\section{Limitations}

Some of limitations those were frequently faced during this study are summarized below:

1) Cardiac Pacemaker, Cochlear Implants \& some orthopedics prosthesis patient are prohibited for MRI.

2) Cost effective is relatively more than X-ray or CT scan.

3) The sample was taken purposively, so it may not reflect the actual situation.

4) MRI is not available in many rural areas of Bangladesh.

5) Wheel chair or bed patient can't take directly to the MRI.

6) Claustrophobic \& disoriented patients are very difficult to do MRI.

7) MRI takes long time for completing whole scan.

\section{CONCLUSION:}

Knee pain is very common nowadays and will affect most of us at some point during our lives. From the observations of present study it can be said in conclusion that MRI would be the best choice for diagnosing the reason of knee pain in combination with conventional $\mathrm{x}$-rays. It may affect in diagnosis the exact reason of knee pain as well as management of the knee injuries by reducing the number of arthroscopic procedures, improving doctors' diagnostic certainty, and assisting in management decision. MRI of knee may often be useful during the surgery and also to see the healing progress after surgery of knee. For the rapid, accurate diagnosis with a noninvasive examination of painful knee, MRI examination can be considered as an ideal technique. It had also been demonstrated that MRI is a cost effective technique by reducing unnecessary surgical and arthroscopic interventions (Shah et al., 2014).

\section{ACKNOWLEDGEMENT:}

Firstly, I am grateful to Almighty Allah to give me the ability to complete this project. This research was supported by Department of Biomedical Engineering and Medical Physics of Bangladesh University of Health Sciences. I am thankful to all who provided expertise that greatly assisted the research. Also I would like to thank my parents and my family for supporting me mentally throughout writing this study.

\section{CONFLICTS OF INTEREST:}

The author's declared there are no conflicts of interest to publish the present work.

\section{REFERENCES:}

1) Arumugam $V$, Ganesan GR, Natarajan $P$, (2015). MRI Evaluation of AcuteInternal Derangement of Knee. Open Journal of Radiology, 5, https://doi.org/66-71. 10.4236/ojrad.2015.52011

2) Bansal N, Kaur N, Sandhu K.S. (2018). Role of MRI in the Evaluation of Painful Knee Joint, International Journal of Anatomy, Radiology and Surgery, 7(3): RO27-RO30.

3) Campbell SE, Sanders TG, Morrison WB. (2001). MR imaging of meniscal cysts: incidence, location, and clinical significance. American J. of Roentgenology, 177(2), 409-13.

https://pubmed.ncbi.nlm.nih.gov/11461872/

4) Crues JV, Richard R, Morgan FW. (1990). Meniscal pathology: The expanding role of magnetic resonance imaging. Clinical Orthopaedics and Related Research, 252, 80-86.

5) Dawson J., Linsell L, Zondervan K, Rose P, Randall T, Carr A, Fitzpatrick R. (2004). 'Epidemiology of hip and knee pain and its impact on overall health status in older adults', Journal of Rheumatology, 43(4), 497-504.

https://doi.org/10.1093/rheumatology/keh086

6) Escala JS, et al. (2006). Objective patellar instability: MR-based quantitative assessment of potentially associated anatomical features. Knee Surg Spor. Traumatol Arthrosc. 14(3), 264-272.

7) Gimhavanekar S, Suryavanshi K, Kaginalkar J, Rote-Kaginalkar V, (2016). Magnetic Resonance Imaging of Knee Joint: Diagnosis and Pitfalls Using Arthroscopy as Gold Standard. Int J Sci Stud, 4(1):110-16.

http://www.ijss-sn.com/uploads/2/0/1/5/20153321/ ijss_apr_oa23.pdf

8) Haq SA, Darmawan J, Islam MN, Ahmed M, Banik SK, Fazlur Rahman AKM et al. (2008). 'Incidence of musculoskeletal pain and rheumatic disorders in a Bangladeshi rural community: A WHO - APLAR-COPCORD study. Inter- 
national Journal of Rheumatic Diseases. 11(3): 216-223.

https://research.utwente.nl/en/publications/inciden ce-of-musculoskeletal-pain-and-rheumatic-disor ders-in-a-ba

9) In-Charge I, Technologist I, Radiologist C. (Imaging department, Parami General Hospital, Yangon, Republic of Union of Myanmar), (2019). 'The effectiveness of Diagnostic Imaging with MRI and DR for evaluation of knee related abnormalities' ISRRT Newsletter, 47-49.

10) Kamran S, Haider A, Khalid S, Shah Z,Shahid A, Baseer R, (2015). Role of MRI in Painful knee. Ann.Pak.Inst.Med.sci. 11(3):137-141. https://apims.net/apims_old/Volumes/Vol11-3/R OLE\%20OF\%20MRI\%20IN\%20PAINFUL\%20K NEE-Final.pdf

11) Kelly EA, (2006). Berquist MRI of the musculoskeletal system: Knee ( $5^{\text {th }}$ edn.) Lippincott, Williams and Wilkins, 307-21.

12) Mansour M.A.M, Ahmed R.M, Alaaibrahim, Elhussein N, Aljuaid S.A, (2015). Magnetic resonance imaging diagnostic procedures for knee joint injuries, IOSR-Journal of Nursing and Health Sciences, 4(2), 37-46.

https://doi.org/10.9790/1959-04223746

13) Mathis CE, Noonan K, Kayes K. (1998). "Bone bruises" of the knee: a review. The Iowa Orthopaedic Journal, 18,112-17.

14) McCauley TR, Moses M, Kier R, Lynch JK, Barton JW, Jokl P. (1994). MR diagnosis of tears of anterior cruciate ligament of the knee: importance of ancillary findings. AJR.American journal of roentgenology, 162(1):115-17. https://europepmc.org/article/med/8273648

15) Mehta R, Agrahari N.S, Agarwal S, Bhargava A. (2015). 'MRI detected prevalence of abnormalities in of knee pain' Metha $\mathrm{R}$ et al. Int J Res Med Sci, 3(10), 2572-2575.

http://dx.doi.org/10.18203/2320-6012.ijrms2015 0792

16) Miller TT, Staron RB, Koenigsberg $T$, Levin TL, Feldman F. (1996). MR imaging of Baker cysts: association with internal derangement, effusion, and degenerative arthropathy. Radiology, 201(1), 247-50. https://pubmed.ncbi.nlm.nih.gov/8816552/
17) Miller LS, and Yu JS. (2010). Radiographic indi-cators of acute ligament injuries of the knee: a mechanistic approach. Emerg Radiol. 17(6), 435-44. https://pubmed.ncbi.nlm.nih.gov/20490594/

18) Pame M, Gayan M, Hazarika K, Roy DKR, (2017). MRI evaluation of painful knee jointthe correlation of multiple coexisting pathologies, age and sex. J Evid Based Med Health, 4(18), 1019-27.

19) Pasupuleti B, Kosti SK, Narra R, Jukuri N. (2015). MRI evaluation of painful knee. $J$ of Evidence Based Med and Health Care, 2(7), 888-97.

20) Peterfy CG, Guermazi A, Zaim S, Tirman PF, Miaux Y, White D, et al. (2004). Whole-organ magnetic resonance imaging score (WORMS) of the knee in osteoarthritis. Osteoarthritis and Cartilage, 12(3), 177-90.

https://pubmed.ncbi.nlm.nih.gov/14972335/

21) Pompan, DC. (2012). Reassessing the role of MRI in the evaluation of knee pain. Am Fam Physician, 85, 221-24.

22) Prickett WD, Ward SI, Matava MJ. (2001). Magnetic resonance imaging of the knee. Sports Med; 31(14): 997-1019. https://pubmed.ncbi.nlm.nih.gov/11735683/

23) Roy K, Hossain S, Saha B, and Roy RC. (2020). Assessment of depression among musculoskeletal fracture patients in a tertiary referral hospital in Bangladesh, Eur. J. Med. Health Sci., 2(6), 134-144. https://doi.org/10.34104/ejmhs.020.01340144

24) Sansone V, de Ponti A, Paluello GM, delMaschio A. (1995). Popliteal cysts and associated disorders of the knee: critical review with MR imaging. IntOrthop, 19(5), 275-79.

25) Saraswathi KP. (2009). 'Analysis of the problems of the aged above 60 years in a selected urban community in Hyderabad', Nursing $J$. of India, 91(4), 86-88.

26) Shah D, Naware S, Bhatnagar S, Kulkarni VM. (2014). Role of magnetic resonance imaging in the evaluation of articular cartilage in painful knee joint. Med J DY Patil Univ,7, 160-65. https://doi.org/10.4103/0975-2870.126326 
27) Singh J.P, Garg L, Shrimali R, Setia V, Gupta V. (2004). MR Imaging of knee with arthroscopic correlation in twisting injuries. Indian journal of radiology and imaging, 14(1), 33-40. https://www.ijri.org/text.asp?2004/14/1/33/28551

28) Sohail K, Ayesha H, Shireen K, Zahir S, Ambreen S, Rehana B. (2015). Role of MRI in painful knee. Ann Pak Inst Med Sci, 11(3), 13741.

https://apims.net/apims_old/Volumes/Vol11-3/R OLE\% 20OF\%20MRI\%20IN\%20PAINFUL\%20K NEE-Final.pdf

29) Spindler KP, Schils JP, Anderson TE, et al. (1993). Prospective study of osseous, articular, and meniscal lesions in recent anterior cruciate liga-ment tears by magnetic resonance imaging and arthroscopy. The American Journal of Sports Medicine, 21(4), 551-57.

https://pubmed.ncbi.nlm.nih.gov/8368416/

30) Wright DH, De Smet AA, Norris M. (1995). Bucket-handle tears of the medial and lateral menisci of the knee: value of MR imaging in detecting displaced fragments. AJR American Journal of Roentgenology, 165(3), 621-25. https://pubmed.ncbi.nlm.nih.gov/7645481/

31) Yadav R, and Kachewar S. G. (2013). Role of MRI in Evaluation of Painful knee. International J. of Medical Research \& Health Sciences, 3(1). ISSN: 2319-5886.

https://www.ijmrhs.com/abstract/role-of-mri-inevaluation-of-painful-knee-514.html

Citation: Rana S, Hossen M, Islam A, Shah S, Parvin T, Muraduzzaman SM, and Jalali MA. (2021). Interpretation of the common MRI findings in patients with painful knee joint, Eur. J. Med. Health Sci., 3(1), 19-26. https://doi.org/10.34104/ejmhs.021.019026 क) क 